www.jmscr.igmpublication.org

Index Copernicus Value: 79.54

ISSN (e)-2347-176x ISSN (p) 2455-0450

crossref DOI: https://dx.doi.org/10.18535/jmscr/v7i3.241

\title{
Prevalence of Ocular Morbidity in Kashmiri Population Attending Tertiary Eye Care Center
}

\author{
Authors \\ Mehak Mufti ${ }^{*}$, Hammad Nasti ${ }^{2}$ \\ ${ }^{1}$ Assistant Professor, Department of Physiology, GMC, Anantnag \\ ${ }^{2}$ Consultant Al Kabir Eye Care Center, Srinagar, J \&K \\ *Corresponding Author \\ Dr Mehak Mufti
}

Assistant Professor, Department of Physiology, GMC, Anantnag, J\&K., India

Mob: 7889788272, Email: muftimehak@gmail.com

\begin{abstract}
Background: The Prevalence of blindness is reported to be very high (2\% and above) in $J$ \& $K$ with cataract being the leading cause of blindness. Others are uncorrected refractive errors, childhood blindness, glaucoma, diabetic retinopathy. Since major burden of blindness is due to preventable causes, early detection and treatment of ocular morbidity is very important in all the age groups. Therefore we took up the present student with an aim to find out the prevalence of ocular morbidity (irrespective of the age) in Kashmiri population attending a tertiary eye care center.

Materials \& Methods: This is a hospital based cross sectional study which was conducted at Al Kabir Eye care center, Srinagar, $J \& K$ after approval from institutional ethical committee. The data was collected over a period of 2 years (2017 and 2018) from 4595 patients who was then analyzed to find out the prevalence of various ocular morbidities and was expressed in percentage. Detailed ophthalmological examination was done by experienced and qualified ophthalmologists.

Results: Our study shows that the most Prevalent ocular morbidity in the study group was cataract (30\%) followed by refractive errors (21\%), diabetic retinopathy (17\%), glaucoma (15\%), childhood diseases (13\%), squint (3\%) and corneal blindness( $1 \%$ ).

Conclusion: High prevalence of ocular morbidity calls for early screening of the population and creating awareness among them. Since most of the causes of ocular morbidity are preventable therefore educating the masses regarding healthy eye care practices, periodic eye checkups, importance of vitamin $A$ in the diet, availability of subsidized cataract surgeries and other eye care services is important.
\end{abstract}

\section{Introduction}

India is home to $23.5 \%$ of the world's blind population and the prevalence of blindness was estimated to be $1.38 \%$, although it varied from $0.44 \%$ to $2.8 \%$ in different states. The prevalence was reported to be very high ( $2 \%$ and above) in states like Madhya Pradesh, Rajasthan, Jammu and Kashmir whereas Delhi, Punjab, Himachal Pradesh, West Bengal, the prevalence was reported to be less than $1 \% .^{1,2}$

Almost all survey in the country show that cataract is the most common cause of blindness, others being uncorrected refractive errors, childhood blindness, corneal blindness, glaucoma, 
diabetic retinopathy and trachoma. ${ }^{3,4,5}$ Childhood blindness alone accounts to $28.7 \%$ of the economic burden in India. Vitamin A deficiency, corneal diseases, meseals, opthalmia neonatorum, trauma are some of the causes of the childhood blindness in India ${ }^{6,7,8}$. It is important to prioritize childhood blindness and develop preventive and curative services for children considering the fact that they cannot clearly complain of their problems and even be aware of them and also considering the number of years of disability they will have to live with. Also with the increasing population and an enhanced lifespan, there is increase in the number of cataracts, glaucoma, diabetic retinopathy, age related macular degeneration, retinal detachment, macular scars and refractive errors. The pattern and etiology of visual impairment varies with age. ${ }^{9}$

Since major burden of blindness is due to preventable causes, early detection and treatment of ocular morbidity is very important in all the age groups. Most of the prevalence studies done are in children and are community based where most of the examination is done by torch light. Therefore we felt the need for the present study where a detailed Opthalmological examination of all the patients was done by experienced Opthalmologists using the most sophisticated equipments.

We took up the present student with an aim to find out the prevalence of ocular morbidity (irrespective of the age) in Kashmiri population attending a tertiary eye care center located in Srinagar city $\mathrm{J} \& \mathrm{~K}$.

\section{Materials and Methods}

This is a hospital based cross sectional study which was conducted at Al Kabir Eye care center, Srinagar, J\&K after approval from institutional ethical committee. The data was collected over a period of 2 years (2017 and 2018). The data of 4595 patients attending at $\mathrm{Al}$ Kabir Eye care center over a period of these two years was then analyzed to find out the prevalence of various ocular morbidities and was then expressed in percentage. Detailed ophthalmological examination was done by experienced and qualified ophthalmologists. Visual acuity was checked for both near and far vision, anterior segment was examined by slit lamp biomicroscopy, dilated fundus examination was done by slit lamp biomicroscopy, intraocular pressure was measured by applantation tonometer.

\section{Results}

Our results show that cataract is the most prevalent form of ocular morbidity in the study population, followed by refractive errors, diabetic retinopathy, glaucoma, childhood blindness, squint and corneal blindness. The number of cases and the percentage wise result is expressed in table 1 and figure 1 respectively.

Table 1: Prevalence of ocular morbidity in kashmiri population, attending a tertiary eye care center .

\begin{tabular}{|l|c|}
\hline Ocular morbidity & $\begin{array}{c}\text { No of cases reported } \\
(\mathrm{N}=4595)\end{array}$ \\
\hline Cataract & 1391 \\
\hline Refractive errors & 982 \\
\hline Diabetic retinopathy & 782 \\
\hline Glaucoma & 668 \\
\hline Childhood diseases & 593 \\
\hline Squint & 114 \\
\hline Corneal blindness & 65 \\
\hline
\end{tabular}

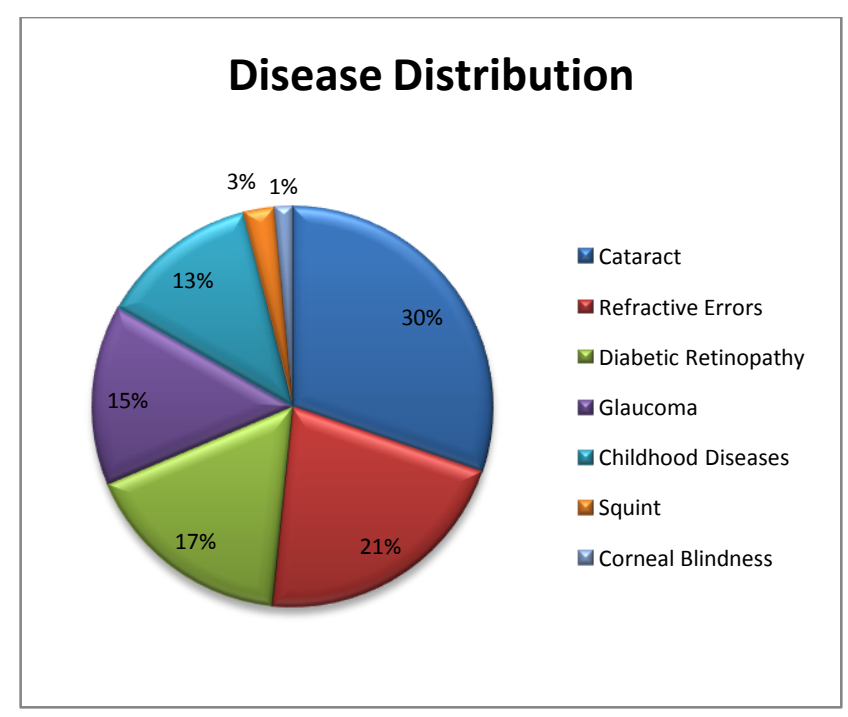

Figure 1: Shows the pattern of disease distribution in kashmiri population 


\section{Discussion}

Our results show cataract is the most prevalent ocular morbidity followed by refractive errors, diabetic retinopathy, glaucoma, childhood blindness, squint and corneal blindness. There was no case of trachoma and retinopathy of prematurity in these two years. Childhood blindness included cases of ptosis, congenital refractive errors, congenital defects in the iris, coloboma.

Studies by Jitendra kumar et al show high prevalence of cataract, refractive errors and corneal opacity, all of which is treatable . ${ }^{10}$ Venkataramana et al in their study on 1181 people showed that most prevalent ocular morbidity was refractive errors $(6.4 \%)$ followed by cataract (4\%), corneal blindness (3\%) and that ocular morbidity was 4.49 times more prevalent in the age group of 46-60 years and 20.64 times more in diabetic population as compared to non diabetics. ${ }^{11}$ Vibha Baldev et al in their study on 900 eyes found visual impairment in $30 \%$ and blindness in $8 \%$ of the study population. Visual impairment was more in individuals with low socioeconomic status. ${ }^{9}$ In a community based cross sectional study on 925 subject, common ocular morbidities reported were myopia, conjuctival xerosis, hypermetropia, xeropthalmia, pterygium, immature senile cataract, eye strain followed by presbyopia and females were affected more than males. Ocular morbidity is more prevalent in rural areas. ${ }^{12}$

More literature however is available regarding ocular morbidities in school going children which have shown refractive errors to be most prevalent among them. ${ }^{13,14,15,16}$

\section{Conclusion}

High prevalence of ocular morbidity calls for early screening of the population and creating awareness among them. Cataract and refractive errors are both preventable causes of blindness, therefore educating the masses regarding healthy eye care practices, importance of vitamin $\mathrm{A}$ in the diet, availability of subsidized cataract surgeries and other eye care services is important.

Source of funding: none

Conflict of interest: None

Ethical clearance: taken

\section{References}

1. Angra SK, Murthy GV, Gupta SK et al. Cataract related blindness in India and its social implications. Indian $\mathrm{J}$ Med Res 1997:106;312-24

2. Bhaduri G:National Programme for control of Blindness. A review.Indian $\mathrm{J}$ Public Health 1997;41(25-30):32

3. Bourne RRA, Flaxman SR, Braithewaite T et al . Magnitude, temporal trends and projections of the global prevalence of blindness and distance and near vision impairement a systematic and meta analysis.Lancet Glob Health 2017;5(9):888-97

4. Thomas R, Paul P, Rao GN et al. Present status of eye care in India.Survo Opthal 2005;50(1):85-101

5. Rehman S, Kaunsar R, Kadri SM. Prevalence of bilateral cataract in persons $>50$ years of age in Pulwama district, Jammu \&Kashmir, India.

6. Rahi JS, Sripathi S,Gilbert CE et al. Childhood blindness in India:causes in 1318 blind school students in nine states .Eye1995; 9:545-50

7. Shamanna BR, Dandona L, Rao GN; Economic burden of blindness in India. Indian J Opthalmol 1998;46:169-72

8. Mahesh KM, John D, Rose A, et al. Prevalence of ocular morbidity among tribal children in Jawadi hills, southern India: A cross sectional study. Indian J Opthalmol 2019;67(3)386-90

9. Baldev VF, Chopra R, Batra $\mathrm{N}$ et al. Pattern of ocular morbidity in the elderly population of northern India. J Cli nical diagnostic Res 2017; 
10. Kumar J, Sirohi N, Tiwari N. Ocular morbidity among elderly population in rural areas of Bundelkhand. IOSR J dental med sci. 2016; 15(6):5-10.

11. Venkataramana, Amarnath RLC. Prevalence and pattern of ocular morbidity and factors influencing ocular infleincing ocular morbidity in rural population in south india: a community based cross sectional study. Int J Community Med Public Health 2017;4(8):2939-45.

12. Shrote VK, Thakre S, Lanjewar AG et al . Ocular morbid conditions in rural areas of central India.Int J collaborative Research on internal Med and public health.

13. Gupta M, Gupta BP, Chauhan A et al. Ocular morbidity prevalence among school children in Shimla, Himachgal, North India. Indian $\mathbf{J}$ Opthalmol 2009;57:133-38

14. Nepal BP,Koirala S, Adhikary S et al . Ocular morbidity in school children in Kathmandu. Br J Opthalmol 2008;87:5314

15. Awan AR, Jamsheed J, Mushtaq MK et al. Prevalence and causes of visual impairement and blindness among school children in Muzaffarabad, Pakistan. Int J Sci Rep 2018;4(4):93-98

16. Madhavi MR, Kesuraju V, Nagrale P et al. Ocular morbidity among school children in Indian scenario. Int $\mathrm{J}$ Med Sci 2015;3(6):1431-34. 